Emergency care

\section{Restructuring our workforce}

\section{J P Wyatt}

\section{Decisions about developing new roles in the emergency department may have to be taken soon if the service is to be maintained}

$\mathrm{P}$ roviding high quality emergency care to acutely ill and injured patients has become more challenging than ever. There are increasing pressures from all sorts of different directions. Patients quite rightly expect better treatment, delivered with better communication. At the same time, emergency treatments have become increasingly sophisticated. As a result, it might be expected that it would take longer for staff to provide high quality care. Indeed, there is already some evidence (presented in this journal) that this is the case. ${ }^{1}$ All of these pressures are occurring in the context of overcrowded accident and emergency (A\&E) departments and the government having set "performance targets" that focus heavily upon the rate of processing patients. ${ }^{2}$

The pyramidal medical staffing structure of A\&E departments in the UK has meant that it has traditionally fallen upon junior doctors (especially senior house officers) to provide most of the emergency care. The European Working Time Directive and other restrictions on junior doctors' hours have already begun to have an impact on the way that the A\&E service is delivered. Further changes are inevitable. The most obvious changes will result from the implementation of the proposals set out in "Unfinished Business" and "Modernising Medical Careers". ${ }^{34}$ The introduction of foundation programmes will undoubtedly change the role of the senior house officer in a significant way in the next few years. For these junior doctors, the balance between service and training will shift more towards training. A\&E departments will have to seek out alternative ways of delivering the service. Changing the roles of existing staff and developing the roles of new staff may help to achieve this. Some developments (such as emergency nurse practitioners) are so widespread that they may be reasonably considered to be the norm, while other innovations (such as paramedic emergency care practitioners and physician assistants) are largely untested in the UK. ${ }^{5}$

The paper by Mitchell et al in this issue of the journal shows that a significant proportion of the time of a junior doctor in A\&E is spent performing administrative and technical tasks that might be easily undertaken by other suitably trained people. ${ }^{7}$ Mitchell et al suggest that physician assistants would be ideally placed to fulfil some of these roles. The concept of physician assistants may appear to be comparatively new in the UK, but they are already well established in the USA. ${ }^{8}$ The US physician assistants have developed their own professional identity. They typically follow a background of study of a medically related subject at college by a further period of university study. Physician assistants are inherently dependent practitioners, working alongside a designated physician. They seem to be most effective when the relationship between the physician assistant and the physician is harmonious and well established. In this respect, it would seem more sensible for the physician assistant to work directly with a more senior and experienced doctor, rather than an inexperienced junior doctor who only works for a short period in A\&E. Given the nature and rate of change facing UK A\&E departments, decisions about developing new roles may have to be taken in the very near future if the service is to be maintained.

Emerg Med J 2004;21:526.

doi: 10.1136/emj.2003.011791

Correspondence to: Mr J P Wyatt, Department of Accident and Emergency, Royal Cornwall Hospital, Treliske, Truro, Cornwall TR1 3L, UK; jonathan.wyat!@rcht.cornwall.nhs.uk

\section{REFERENCES}

1 Gilligan P, Illingworth RN, Crane S, et al. Are accident and emergency senior house officers getting slower? Emerg Med J 2004;21:646.

2 Lammy D. Reforming emergency care; for patients. Emerg Med J 2003;20:112.

3 Chief Medical Officer. Unfinished business: proposals for reform of the senior house officer grade. London: Department of Health, 2002.

4 Department of Health. Modernising medical careers: the next steps, 2004. hitp:// www.mmc.nhs.uk.

5 Law H, Sloan J. Doctor's assistants-do we need them? J Accid Emerg Med 1999; 16:1 14-16.

6 Scott J, Carney C. Emergency care practitioners. Emerg Med J 2004;21:273-4.

7 Mitchell J, Hayhurst C, Robinson S. Can a senior house officer's time be used more effectively? Emerg Med J 2004;21:545-7.

8 Wyatt JP, Weber JE, Chudnofsky C. The work of the American emergency physician. J Accid Emerg Med 1998;15:170-4.

9 Hutchinson L, Marks T, Pittilo M. The physician assistant: would the US model meet the needs of the NHS? BMJ 2001;323:1244-7.

\title{
Defining the specialty
}

\section{J Clancy}

\section{Curriculum and textbook initiatives}

t is now 30 years since the first consultants in accident and emergency medicine were appointed. The Faculty of Accident and Emergency Medicine celebrated its first decade in
November 2003. We live in turbulent times with service pressures increasing while others outside our specialty (not fully understanding what we do) seek solutions for the provision of emergency care by looking outside the emergency department.

Perhaps now more than ever we need to take stock of our specialty. We need to define what knowledge, skills, and attributes we expect of all future consultants, so that a consistently high quality service can be assured within the boundaries we choose. By specifying what we do and don't do, it becomes clear to both ourselves and others what should happen in emergency departments and therefore the resources that are needed and the training that is required.

By saying what we do, we define our specialty, our service, and our syllabus. 


\section{EDITORIALS}

This does not mean that we cannot develop our own interests and expertise but this would be in addition to the defined "core" activity that we think should be common to all UK A\&E consultants. To get things right for the consultants of the future, we need to define what our core function will be in five to eight years time.

Those of us who have been consultants for some years may be apprehensive about such an exercise. There may be many things we need to know that we were not taught or where the opportunities to gain the necessary knowledge and skills are limited. These difficulties, however, should not stop us taking on these changes.

The faculty has the role of identifying what our practitioners need to know and also the role of providing educational experiences that may be required.

Some will be concerned that the specialty that is developing (and that we are attempting to define) is very different from the specialty they signed up for either as trainees or consultants.

It is because we lack the precision of a detailed definition of what we are that we are in this dilemma.

One of the key issues to be tackled is how long should we look after patients. The government is defining our specialty by a four hour target. Should we have the skills to look after certain groups of patients for longer? Should observational medicine be a core part of our practice? Should we be aiming to equip future trainees with advanced airway skills?

These are challenging issues, but the need to take a position on them is imperative.

The combination of Modernising Medical Careers, the European Working Time Directive, Reforming Emergency Care, and the reconfiguration of acute hospitals means that the existing pattern of the provision of A\&E medicine is set to change.

We cannot define our future by basing it simply on what we have done in the past.
How do we set about this process? It is proposed that we build on the hard work of others who have developed the present faculty syllabus, by developing an understanding of the syllabuses of the other major emergency medicine training groups such as ACEP, ACEM, CAEM. We will use the key features of our own syllabus, and those of others, to define what our core knowledge and competencies should be.

To achieve this, we need to provide a framework that enables wide participation. It is proposed to split the syllabus into a number of areas that will then be scrutinised in detail by interested, knowledgeable practising clinicians. They will be asked to give as much detail as possible as to what should be known about specific topics, adding topics that are currently not specified. They will be asked to identify those items that must be known (to make up the core) and those about which there should be an awareness. This work will be supervised by a standing committee who are tasked with ensuring maintenance and updating of the syllabus. New areas of development will be identified and highlighted. Each year the faculty will endeavour to provide educational opportunities to ensure all members are aware of these new areas. In this way the syllabus becomes a working document that is updated and identifies our knowledge needs both for those in training and those who have completed their SpR training. The regular updating of the syllabus can be used to help guide CPD by identifying those areas in which significant recent changes may have taken place.

In tandem with the development of this list of subjects (the syllabus) will be suggestions as to how the knowledge and skills maybe gained and assessed.

It is hoped that some of these educational needs that have necessitated attachment outside the department, for example, anaesthesia and intensive care, may be met in a new and more structured basic specialty training programme.
In that situation secondments would no longer be a dominant feature of registrar training. Those trainees who require further focused study in a particular area could undertake a "virtual secondment", by spending time within the department as the doctor of first contact for a series of patients and then following them through to their definitive care in another department. For instance, currently to gain knowledge of ENT emergencies, a trainee may end up sitting in an outpatient department seeing many children with hearing difficulties. It may be better that the trainee is enabled to monitor 10 patients with epistaxis or foreign bodies through to the ENT department. The experience would thus start in the emergency department and go through to the specialist department rather than being within the specialist department alone.

As an integral part of this development the faculty is embarking on an ambitious project of providing a textbook that will meet the needs of all doctors working in the emergency department. The syllabus will provide the road map for the textbook that will ultimately be in electronic format. It is intended that it will meet the needs of those preparing for all three parts of the faculty examination and define the knowledge base and competencies required for independent practice in our specialty.

These are huge undertakings. If they are to be completed the energy and ability of many will be needed. These are essential steps in defining who we are and what our specialty is.

If you would like to be involved in defining part of the syllabus in greater detail, or in preparing a subject area for the textbook then email the Faculty of Accident and Emergency Medicine (faem@emergencymedicine.uk.net).

Emerg Med J 2004;21:526-527.

doi: 10.1136/emj.2003.009522

Correspondence to: Mr M J Clancy, Accident and Emergency Department, Southampton General Hospital, Tremona Road, Southampton SO166YD, UK; clancm@hotmail.com 